\title{
ANALISA KINERJA BUS RAPID TRANSIT (BRT) TRANS SEMARANG KORIDOR II TERMINAL TERBOYO-TERMINAL SISEMUT
}

\author{
Agnesia Putri Kurnianingtyasa ${ }^{a}$ A izzatul Mardliyah ${ }^{b}$, Kiki Lana Fauzizah ${ }^{c}$ \\ a Program Studi Perencanaan Wilayah dan Kota Fakultas Teknik Universitas Semarang; Jl. Soekarno Hatta, Tlogosari \\ Kulon, Kec. Pedurungan, Kota Semarang, Jawa Tengah 59160; agnesiaputri@usm.ac.id \\ bc Program Studi Perencanaan Wilayah dan Kota Fakultas Teknik Universitas Semarang; Jl. Soekarno Hatta, Tlogosari \\ Kulon, Kec. Pedurungan, Kota Semarang, Jawa Tengah 59160
}

Info Artikel:

- Artikel Masuk: 19/09/20

- Artikel diterima: $17 / 10 / 20$

- Tersedia Online: 30/10/20

\begin{abstract}
ABSTRAK
Kota Semarang sebagai salah satu kota besar di Jawa Tengah telah mengembangkan transpotasi umum yaitu Bus Rapid Transit (BRT) sebagai upaya untuk mengurangi kemacetan dan mengurangi penggunaan kendaraan pribadi di Kota Semarang. Hingga tahun 2021 ini, terdapat 8 koridor utama dan 1 koridor khusus BRT yang sudah dikembangkan, salah satunya adalah koridor II yang melayani rute Terboyo-Sisemut. Penelitian ini bertujuan untuk menganalisis kinerja pelayanan BRT Koridor II secara berkelanjutan dengan pengoptimalisasi penggunaan BRT rute Terboyo-Sisemut sehingga dapat ditemukan faktor - faktor permasalahan yang mempengaruhinya dan dapat dirumuskan langkah - langkah perbaikan dan peningkatan mutu pelayanannya. Metode yang digunakan dalam penelitian ini adalah metode kuantitatif yaitu dengan melakukan penghitungan nilai bobot melalui indikator-indikator penilaian berdasarkan standar Dirjen Perhubungan. Indikatorindikator tersebut diperoleh dari hasil survey dinamis dan survey statis. Dari hasil analisa, kinerja pelayanan BRT Koridor II Terminal Terboyo-Terminal Sisemut PP termasuk kategori baik. Kebutuhan jumlah armada pada koridor II yaitu sebanyak 21 unit. Berdasarkan hasil evaluasi, dapat diberikan beberapa rekomendasi salah satunya yaitu pembuatan jalur khusus untuk BRT agar waktu perjalanan lebih cepat, sehingga pengguna lebih minat dalam menggunakan BRT.
\end{abstract}

Kata Kunci: kinerja pelayanan, transportasi, angkutan umum, BRT

\begin{abstract}
Semarang as one of the big cities in Central Java has provided public transportation which is Bus Rapid Transit (BRT) as an effort to reduce congestion and the use of private transpotation. There are eight main corridor and one special corridor that are provides until 2021, one of them is Corridor II with Terboyo-Sisemut Route. This study is aim to analyze the servce performance of Corridor II with the optimalization the use of BRT in this route, find the problem factors that influence and formulate the step for quality services improvement. The method of this study is quantitative method by calculating the weight value through assessment indicators based on the standards of the Director General of Transportation. These indicators are obtained from the results of dynamic surveys and static surveys. From the analysis, the service performance of BRT Corridor II at Terminal Terboyo-Sisemut PP is in good category. The number of fleets needed in corridor II is 21 units. Based on the results of the evaluation, one recommendation to improve the quality service of BRT is to make a special lane for BRT to make travel time faster, so that users are more interested in using BRT.
\end{abstract}

Keyword: service performance, transportation, public transportation, BRT

\section{PENDAHULUAN}

Transportasi merupakan bidang kegiatan yang sangat penting dalam kehidupan manusia, salah satunya adalah transportasi umum atau angkutan umum. Sebagai bagian dari transportasi perkotaan, angkutan umum memegang peranan penting dalam mendukung mobilitas masyarakat. Oleh karenanya, penataan sistem transportasi umum harus dilakukan secara terpadu agar dapat mewujudkan pelayanan jasa transportasi yang seimbang dengan tingkat kebutuhan/permintaan yang layak dan dapat terjangkau oleh seluruh masyarakat. Penataan angkutan umum perkotaan ini dalam jangka panjang diharapkan dapat mengurangi ketergantungan masyarakat terhadap penggunaan kendaraan pribadi.

Salah satu upaya penyediaan layanan angkutan umum di Kota Semarang adalah penyediaan Bus Rapid Transit (BRT) yang dikembangkan sejak tahun 2010. Pengembangan BRT ini dilatarblekalangi karena permasalahan transportasi yang semakin tinggi 
di Kota Semarang, diantaranya adalah masalah tingginya penggunaan kendaraan pribadi yang menyebabkan kemacetan.

Hingga tahun 2020 telah terdapat 8 koridor utama dan 1 koridor khusus yang dilayani oleh BRT Trans Semarang. Salah satu diantaranya adalah koridor II yang melayani rute Terminal Terboyo-Terminal Sisemut PP yang mulai beroperasi dari tahun 2012. Di tahap awal, jumlah armada yang digunakan adalah sebanyak 10 bus, dan pada tahun 2020 ini jumlah armada meningkat menjadi 21 bus. Peningkatan jumlah armada ini menunjukkan adanya peningkatan komitmen Pemerintah Kota Semarang dalam penyediaan transportasi umum dan adanya peningkatan minat masyarakat untuk menggunakan transportasi umum terutama BRT.

Namun dalam pelaksanaannya, pengoperasian BRT masih ditemui beberapa kendala diantaranya terjaur sarana prasarana yang kurang memadai, tingkat kenyamanan, dan penumpang yang melebihi kapasitas. Oleh karena itu perlu dilakukan penelitian untuk mengkaji kinerja pelayanan BRT Koridor II ini untuk kemudian dapat diperoleh kesimpulan terkait kinerja pelayanan dan rekomendasi untuk meningkatkan kualitas pelayanan dan mencapai transportasi berkelanjutan untuk BRT Kota Semarang khususnya Koridor II TerboyoSisemut.

\section{TINJAUAN PUSTAKA}

\subsection{Pengertian Sistem Transportasi}

Transportasi dapat diartikan sebagai suatu upaya untuk memindahkan menggerakkan, mengangkut, atau mengalihkan suatu objek dari suatu tempat ke tempat lain (Miro dalam Nadi, 2018). Steenbrink dalam nadi (2018) menambahkan bahwa transportasi merupakan perpindahan orang dan atau barang dengan menggunakan alat atau kendaraan ke tempat tertentu yang berbeda secara geografis.

Munawar dalam Safe (2015) menyatakan bahwa sistem transportasi memiliki satu kesatuan definisi yang terdiri atas: sistem, yakni bentuk keterikatan dan keterkaitan antara satu variabel dengan variabel lain dalam tatanan yang terstruktur, serta transportasi yakni kegiatan pemindahan penumpang dan barang dari satu tempat ke tempat lain. Dengan kata lain, transportasi dapat diartikan sebagai suatu hubungan yang saling terkait antara berbagai variabel dalam suatu kegiatan pemindahan orang dan atau barang dari satu tempat ke tempat lain.

\subsection{Angkutan Umum}

Angkutan umum merupakan angkutan penumpang yang dilakukan dengan sewa atau berbayar (Warpani dalam Safe, 2015). Hal ini juga sejalan dengan Keputusan Menteri No. 35 Tahun 2003, angkutan umum adalah setiap kendaraan bermotor yang disediakan untuk dipergunakan oleh umum dengan dipungut biaya baik secara langsung maupun tidak langsung.

Pengadaan angkutan umum penumpang bertujuan untuk memberikan pelayanan angkutan yang baik dan layak bagi masyarakat. Tidak hanya itu, pengadaan angkutan umum juga bertujuan untuk mengurangi volume lalu lintas kendaraan pribadi sehingga dapat mengurangi kemacetan. Pengadaan angkutan umum sebagai angkutan yang bersifat massal juga bertujuan untuk menekan biaya angkut serendah mungkin karena biaya angkut dapat dibebankan kepada lebih banyak orang atau penumpang (Warpani dalam Safe, 2015). Dengan biaya angkut yang lebih rendah, maka orang yang tidak memiliki kendaraan pribadi dapat memiliki kesempatan dan kepuasan ekonomi-sosial dalam melakukan perjalanannya.

Pelayanan angkutan umum yang ideal terdiri dari beberapa kriteria yaitu (Pradita, 2016):

a. Keandalan: setiap saat tersedia, kedatangan dan sampai tujuan tepat waktu, waktu tunggu singkat, sedikit berjalan kaki ke bus stop dan tidak perlu berpindah kendaraan.

b. Kenyamanan: pelayanan yang sopan, terlindung dari cuaca yang buruk di bus stop, mudah naik dan turun kendaraan, tersedia tempat duduk setiap saat, tidak berdesakan, interior yang menarik dan tempat duduk yang enak.

c. Keamanan: terhindar dari kecelakaan, badan terlindung dari luka benturan dan bebas dari kejahatan.

d. Murah: ongkos relatif murah dan terjangkau.

e. Waktu Perjalanan: waktu perjalanan singkat. 

2.3. Standar penilaian indikator kinerja pelayanan angkutan umum
Terdapat beberapa parameter untuk mengukur mengukur tingkat keberhasilan atau kinerja sistem angkutan. Parameter tersebut meliputi parameter kuantitatif berupa tingkat pelayanan dan parameter kualitatif berupa mutu
a. Penentuan indikator unjuk kinerja pelayanan
b. Penentuan standar pelayanan
c. Penerapan standar pelayanan menurut ukuran kota dan jenis trayek berdasarkan perhitungan dan pembobotan standar pelayanan pelayanan.

Pemerintah melalui Departemen Perhubungan telah menetapkan standar pelayanan untuk angkutan umum sebagai berikut (Supriyadi, 2003) :

1. Ruang lingkup.

Ruang lingkup evaluasi pengoperasian angkutan umum terhadap standar pelayanan yang ada, meliputi :
2. Pembobotan

Pembobotan yang dilakukan terhadap performasi pelayanan/pengoperasian angkutan umum adalah sebagai berikut :

a. Nilai bobot 1 untuk standar pelayanan dengan kriteria kurang

b. Nilai bobot 2 untuk standar pelayanan dengan kriteria sedang

c. Nilai bobot 3 untuk standar pelayanan dengan kriteria baik.

Tabel 1 Ketentuan Jenis Angkutan Berdasarkan Ukuran Kota dan Trayek (Keputusan Dirjen Perhubungan No 687, 2002)

\begin{tabular}{|c|c|c|c|c|}
\hline \multirow[b]{2}{*}{$\begin{array}{l}\text { Klasifikasi } \\
\text { Trayek }\end{array}$} & \multicolumn{4}{|c|}{ Ukuran Kota } \\
\hline & $\begin{array}{l}\text { Kota Raya } \\
>1.000 .000 \\
\text { penduduk }\end{array}$ & $\begin{array}{l}\text { Kota besar } \\
500.000- \\
1.000 .000 \\
\text { penduduk }\end{array}$ & $\begin{array}{l}\text { Kota Sedang } \\
100.000-600.000 \\
\text { penduduk }\end{array}$ & $\begin{array}{l}\text { Kota Kecil } \\
<100.000 \\
\text { penduduk }\end{array}$ \\
\hline \multirow{2}{*}{ Utama } & Kereta Api & \multirow{2}{*}{ Bus Besar } & \multirow{2}{*}{$\begin{array}{l}\text { Bus Besar/ } \\
\text { Sedang }\end{array}$} & \multirow{2}{*}{ Bus Sedang } \\
\hline & Bus Besar & & & \\
\hline Cabang & Bus Besar/ Sedang & Bus Sedang & $\begin{array}{l}\text { Bus Sedang/ } \\
\text { Kecil }\end{array}$ & Bus Kecil \\
\hline Ranting & Bus Besar/ kecil & Bus Kecil & $\begin{array}{l}\text { MPU (hanya roda } \\
\text { empat) }\end{array}$ & $\begin{array}{l}\text { MPU (hanya } \\
\text { roda empat) }\end{array}$ \\
\hline Langsung & Bus Besar & Bus Besar & Bus Sedang & Bus Sedang \\
\hline
\end{tabular}

Indikator kinerja pelayanan adalah suatu bentuk konsep yang tepat yang merupakan suatu ukuran atau cara untuk mencapai tujuan, menyangkut aspek ekonomi dan teknik atau pengoperasian dari kinerja sistem. Untuk mengetahui apakah angkutan umum tersebut sudah berjalan dengan baik atau belum, dapat dievaluasi dengan memakai indikator pelayanan yang ditetapkan oleh pemerintah melalui Direktorat Jenderal Perhubungan Darat seperti pada tabel 2 berikut:

Tabel 2 Indikator Standar Pelayanan Angkutan Umum Menurut Dirjen Perhubungan Darat (Keputusan Dirjen Perhubungan No 687, 2002)

\begin{tabular}{|c|c|c|c|c|c|c|c|c|}
\hline Nilai & $\mathbf{1}$ & $\mathbf{2}$ & $\mathbf{3}$ & $\mathbf{4}$ & $\mathbf{5}$ & $\mathbf{6}$ & $\mathbf{7}$ & $\mathbf{8}$ \\
\hline 1 & $>1$ & $>15$ & $>12$ & $<13$ & $<4$ & $<82$ & $>30$ & $05.00-18.00$ \\
\hline 2 & $0.8-1$ & $10-15$ & $6-12$ & $13-15$ & $4-6$ & $82-100$ & $20-30$ & $05.00-20.00$ \\
\hline 3 & $<0.8$ & $<10$ & $<6$ & $>15$ & $>6$ & $>100$ & $<20$ & $05.00-22.00$ \\
\hline
\end{tabular}


Seluruh penilaian setiap kolom indikator kemudian dijumlahkan untuk diketahui total nilai bobot dan dinilai kualitas pelayanannya dengan menggunakan tabel 3 berikut:

Tabel 3 Standar Kinerja Pelayanan Angkutan Umum Berdasarkan Total Nilai Bobot (Keputusan Dirjen Perhubungan No 687, 2002)

\begin{tabular}{|l|l|}
\hline Kriteria & Total nilai bobot \\
\hline Baik & $18,00-24,00$ \\
\hline Sedang & $12,00-17,99$ \\
\hline Kurang & $<12$ \\
\hline
\end{tabular}

2.4. Kinerja operasional pelayanan angkutan umum

1. Faktor muat (load factor) dinamis

Trayek tetap dan teratur, mendefinisikan faktor muat (load factor) merupakan perbandingan antara kapasitas terjual dan kapasitas tersedia untuk satu perjalanan yang dinyatakan dalam persen (\%). Untuk menentukan load factor digunakan rumus di bawah:

Load Factor $=\frac{\text { jumlah penumpang }}{\text { kapasitas }} \times 100 \%$

2. Waktu perjalanan

Waktu perjalanan adalah waktu yang dibutuhkan oleh kendaraan untuk melewati ruas jalan yang diamati, termasuk waktu berhenti untuk menaikkan dan menurunkan penumpang dan perlambatan karena hambatan. Waktu perjalanan dirumuskan sebagai berikut:

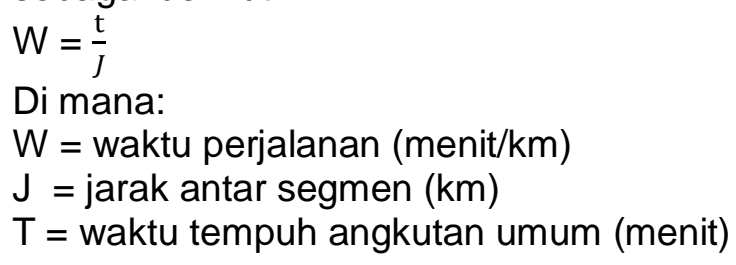

3. Kecepatan perjalanan

Kecepatan adalah tingkat pergerakkan lalu lintas atau kendaraan tertentu yang sering dinyatakan dalam kilometer per jam. Kecepatan perjalanan dirumuskan sebagai berikut :

$$
K=\frac{600 j}{w}
$$

$$
\begin{aligned}
& \text { Di mana: } \\
& \mathrm{K}=\text { kecepatan perjalanan }(\mathrm{km} / \mathrm{jam}) \\
& \mathrm{J}=\text { panjang rute } / \text { seksi jalan }(\mathrm{km}) \\
& \mathrm{W}=\text { waktu tempuh (menit) }
\end{aligned}
$$

4. Frekuensi pelayanan

Frekuensi pelayanan adalah banyaknya kendaraan penumpang umum per satuan waktu, yang besarnya dinyatakan dalam kendaraan/jam atau kendaraan/hari.

5. Waktu antara (headway) dan waktu tunggu Waktu antara (headway) merupakan interval waktu antara saat dimana bagian depan satu kendaraan melalui satu titik sampai saat bagian depan kendaraan berikut melalui titik yang sama. Headway dapat ditentukan menggunakan rumus berikut:

$$
\begin{aligned}
& H=\frac{60}{f} \\
& \text { Di mana: } \\
& H=\text { waktu antara/headway (menit) } \\
& \mathrm{F}=\text { frekuensi }
\end{aligned}
$$

Waktu tunggu dihitung dengan rumus:

Waktu tunggu penumpang $=\frac{1}{2} \times$ waktu headway

6. Jumlah kendaraan yang beroperasi

Jumlah armada operasi adalah jumlah kendaraan peumpang umum dalam tiap trayek yang beroperasi selama waktu pelayanan.

7. Waktu pelayanan

Waktu pelayanan adalah waktu yang dibutuhkan angkutan umum untuk melayani rute tertentu dalam satu hari yang dihitung berdasarkan waktu awal dan waktu akhir dari pelayanan kendaraan penumpang umum tersebut.

8. Penentuan jumlah armada angkutan umum Kebutuhan jumlah armada dapat diestimasikan berdasarkan data headway, kecepatan operasional rata-rata dan panjang rute.

$$
\begin{aligned}
& \mathrm{N}=\frac{\mathrm{lr}}{\mathrm{v}} \times \frac{60}{\mathrm{~h}} \\
& \text { Di mana: }
\end{aligned}
$$


$\mathrm{N}=$ jumlah armada yang dibutuhkan tiap rute per jam

$\mathrm{V}=$ kecepatan operasional rata-rata $(\mathrm{km} / \mathrm{jam})$

$\mathrm{Lr}=$ panjang rute $(\mathrm{km})$

$\mathrm{H}=$ headway (menit)

\section{DATA DAN METODE}

Penelitian ini dilakukan diruas jalan yang dilalui oleh angkutan umum pada koridor II Terminal Terboyo-Terminal Sisemut PP. objek yang ditinjau adalah angkutan umum jenis Bus Rapid Transit (BRT).

Data yang dibutuhkan dalam penelitian ini adalah data primer dan data sekunder. Jenis data primer berupa: pengukuran panjang segmen, waktu perjalanan tiap segmen, jumlah kendaraan yang beroperasi, dan jumlah penumpang naik dan turun tiap segmen. Data sekunder berupa jumlah armada yang terdaftar dan rute trayek BRT.

Data yang sudah diperoleh diolah dalam bentuk tabel, grafik dan gambar. Hasil perhitungan menggunakan rumus-rumus yang menggambarkan indikator-indikator kinerja pelayanan angkutan yang dievaluasi berdasarkan indikator standar pelayanan angkutan umum menurut Direktorat Jenderal Perhubungan Darat. Kemudian dengan memperhatikan tabel standar kinerja pelayanan angkutan umum berdasarkan total nilai bobot. Setelah penilaian kualitas kinerja pelayanan angkutan umum dilakukan, dilanjutkan dengan menghitung kebutuhan armada angkutan umum setiap trayek yang ditinjau.

\section{HASIL DAN PEMBAHASAN}

\subsection{Gambaran Umum Obyek Penelitian}

Koridor II Terminal Terboyo-Terminal Sisemut PP adalah jenis trayek angkutan kota (Angkot). Jumlah BRT menurut ijin yang beroperasi pada trayek ini adalah sebanyak 26 unit dengan jumlah halte estimasi yaitu 74 halte.

\subsection{Analisa Kinerja Operasional Pelayanan Bus Rapid Transit (BRT) koridor II}

1. Faktor Muat (Load Factor) Dinamis Load Factor terjadi pada saat perjananan pergi lebih tinggi dibanding saat perjalanan pulang. Load factor tertinggi BRT koridor 2 Terminal Terboyo - Terminal Sisemut PP terjadi pada shelter Kesatrian sampai BPK B yaitu sebesar $100 \%$. Hal ini terjadi karena jumlah penumpang pada shelter ini cukup padat. Sedangkan Load Factor terendah terjadi pada shelter Terminal Terboyo Sawah Besar sebesar 0 \%. Hal ini terjadi karena tidak adanya penumpang yang naik dari halte Terminal Terboyo, selain itu lokasi shelter kurang strategis berada didalam area Terminal Terboyo sehingga para penumpang lebih memilih naik lewat shelter Sawah Besar.

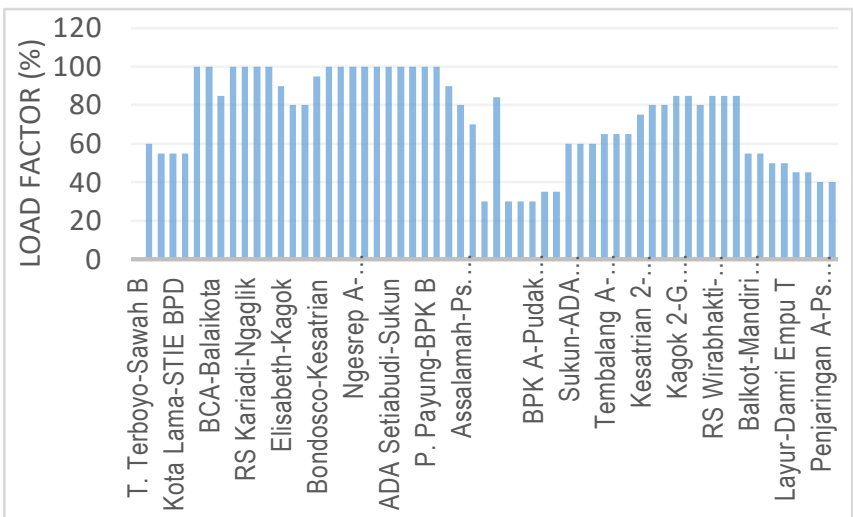

Gambar 1. Load Factor BRT Koridor II Terminal Terboyo - Terminal Sisemut PP (Hasil Analisis, 2020)

2. Waktu Perjalanan

Waktu perjalanan tertinggi BRT koridor II Terminal Terboyo - Terminal Sisemut yaitu 8,8 menit/km pada segmen BPK A sampai Pudak Payung. Dari pengamatan yang dilakukan pada shelter ini arus lalu lintas cukup padat, sehingga menyebabkan lamanya waktu perjalanan. Dapat disimpulkan pada setiap shelter memiliki waktu perjalanan yang berbeda dikarenakan jarak perjalanan dan padatnya lalu lintas. Hal itu yang menyebabkan keterlambatan dalam perjalanan. 


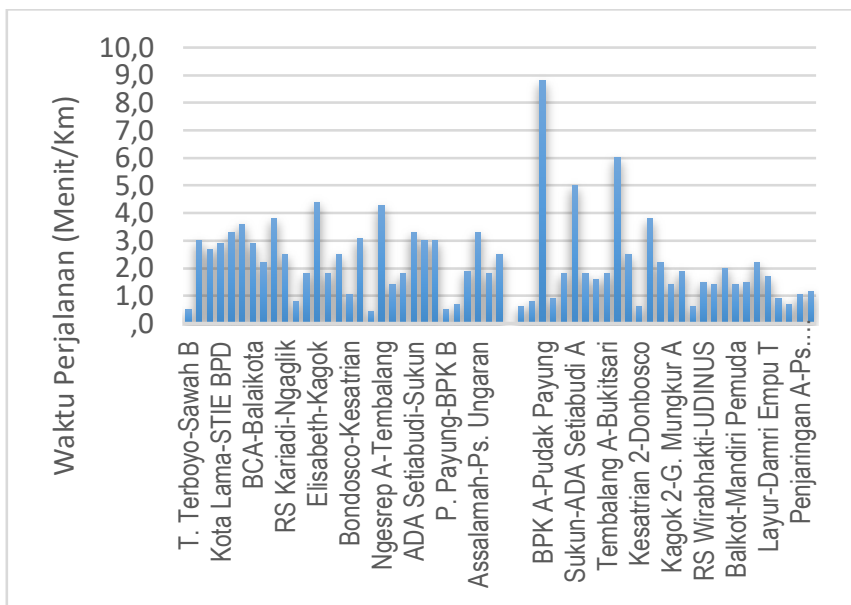

Gambar 2. Waktu Perjalanan BRT Koridor II Terminal Terboyo - Terminal Sisemut PP (Hasil Analisis, 2020)

3. Kecepatan Perjalanan

Kecepatan perjalanan tertinggi trayek Terminal Terboyo-Terminal Sisemut sebesar $50 \mathrm{~km} / \mathrm{jam}$ pada beberapa segmen, dan kecepatan perjalanan terendah adalah 15 $\mathrm{km} / \mathrm{jam}$ yaitu pada segmen Terminal Terboyo sampai Sawah Besar karena pada segmen ini volume kendaran cukup padat karena dekat dengan terminal dan merupakan jalan masuk dari kota lain seperti Demak dan sekitarnya. Dari hasil analisis pada gambar 3 dapat ditarik kesimpulan bahwa tinggi rendahnya kecepatan perjalanan rata-rata setiap segmen dipengaruhi oleh perbedaan karekteristik perjalanan setiap segmen perjalanan, hambatan lalu lintas, waktu berhenti menaikan atau menurunkan penumpang, jarak setiap segmen, serta perilaku dari driver BRT tersebut.

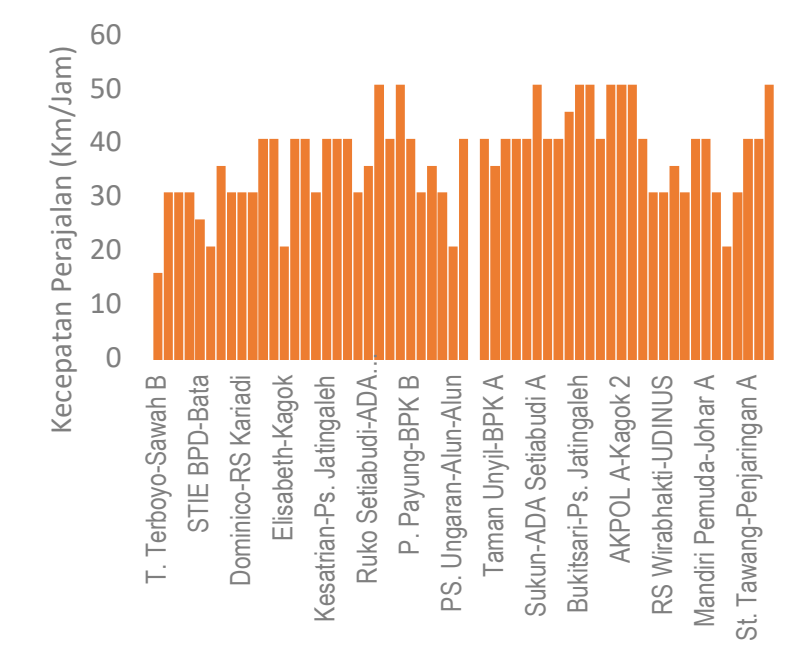

Gambar 3. Waktu Perjalanan Rata-Rata BRT Koridor II Terminal Terboyo - Terminal Sisemut PP (Hasil Analisis, 2020)

4. Frekuensi Pelayanan

Frekuensi pelayanan angkutan umum pada koridor II meningkat pada pukul 06.45-07.45 WIB. Hal ini karena waktu perjalanan angkutan umum yang lebih cepat karena minimnya angkutan yang berhenti untuk menunggu penumpang, serta angkutan umum yang lebih banyak beroperasi. Kemudian sedikit konstan pada rentang pukul 10.45-13.45 WIB, karena pada rentang waktu ini ada angkutan umum yang memiliki waktu perjalanan yang cepat dan lambat, sehingga penyebaran frekuensi pelayanan pada setiap jam pelayanan lebih merata. Lalu pada rentang pukul 14.00-15.45 frekuensi pelayanannya menurun, karena memasuki jam-jam tidak sibuk. Pada jam-jam ini sebagian angkutan umum sedang berhenti beroperasi untuk istirahat. Frekuensi pelayanan meningkat kembali pada jam sibuk sore yaitu pukul 16.45-17.45 WIB. 


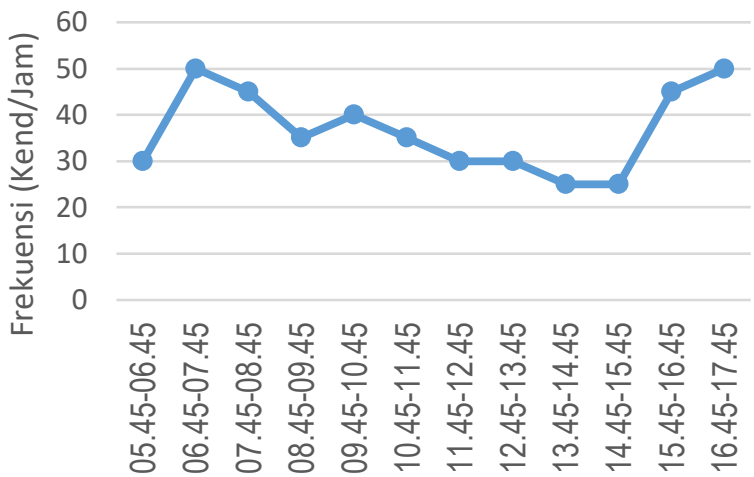

Gambar 4. Frekuensi BRT Koridor II Terminal Terboyo - Terminal Sisemut PP (Hasil Analisis, 2020)

\section{Waktu Antara (Headway)}

Berdasarkan hasil analisis diperoleh nilai headway rata-rata harian koridor II Terminal Terboyo - Terminal Sisemut PP sebesar 2 menit. Hal ini dapat disimpulkan bahwa sangat mudah dalam mendapatkan angkutan umum pada trayek ini.

6. Waktu Tunggu

Dari hasil analisis diperoleh nilai waktu tunggu rata-rata harian koridor II Terminal Terboyo- Terminal Sisemut PP sebesar. Hal ini dapat disimpulkan bahwa penumpang tidak perlu menunggu lama untuk mendapatkan BRT pada trayek ini.

\section{Jumlah Kendaraan Beroperasi}

Persentase kendaraan yang beroperasi pada koridor II Terminal Terboyo - Terminal Sisemut PP sebesar $80 \%$, hasil perhitungan sesuai standar kinerja angkutan umum berbeda dengan perilaku oprasional angkutan umum di lapangan. Hal ini dapat diamati dari perilaku angkutan umum yang berada pada jam sibuk pagi lebih banyak beroprasi karena banyak penumpang. Pada jam tidak sibuk sebagian angkutan umum berhenti istirahat, sedangkan pada jam sibuk sore sebagian angkutan umum memilih untuk lebih duluan berhenti beroprasi.

8. Waktu Pelayanan

Rata-rata awal atau akhir pelayanan angkutan umum adalah antara jam 05.4517.30 WIB untuk trayek Terminal Terboyo Terminal Sisemut PP.

4.3. Kinerja Pelayanan Angkutan Umum Berdasarkan Direktorat Jenderal

Perhubungan Darat

Berdasarkan pada hasil analisis, maka secara keseluruhan kinerja operasional pelayanan BRT Koridor II Terminal TerboyoTerminal Sisemut PP dapat dilihat pada tabel berikut ini:

Tabel 4. Kinerja Operasional Pelayanan BRT Koridor II Terminal Terboyo-Terminal Sisemut PP Berdasarkan Standar Departemen Perhubungan Darat (Hasil Analisis, 2020)

\begin{tabular}{|c|c|c|c|c|c|c|c|c|}
\hline \multirow{3}{*}{ No. } & \multirow{3}{*}{ Parameter Penilaian } & \multirow{3}{*}{ Satuan } & \multicolumn{3}{|c|}{ Standart Penilaian } & \multirow{3}{*}{ Besaran } & \multirow{3}{*}{ Nilai } & \multirow{3}{*}{ Kriteria } \\
\hline & & & Kurang & Sedang & Baik & & & \\
\hline & & & 1 & 2 & 3 & & & \\
\hline 1 & Load Factor Dinamis & $\%$ & $>1$ & $0,8-1$ & $<0,8$ & 72 & 1 & Kurang \\
\hline 2 & Waktu Perjalanan & Menit/Km & $>12$ & $6-12$ & $<6$ & 2 & 3 & Baik \\
\hline 3 & Waktu Antara (Headway) & Menit & $>15$ & $10-15$ & $<10$ & 2 & 3 & Baik \\
\hline 4 & Rata-Rata Waktu Tunggu & Menit & $>30$ & $20-30$ & $<20$ & 10 & 3 & Baik \\
\hline 5 & Waktu Pelayanan & Jam & $<13$ & $13-15$ & $>15$ & 13 & 2 & Sedang \\
\hline 6 & Frekuensi & Kend/Jam & $>4$ & $4-6$ & $>6$ & 36 & 3 & Baik \\
\hline 7 & Jumlah Kend. Beroperasi & $\%$ & $<82$ & $82-100$ & $>100$ & 80 & 1 & Kurang \\
\hline 8 & Awal \& Akhir Perjalanan & Jam & $\begin{array}{l}05.00- \\
18.00\end{array}$ & $\begin{array}{l}05.00- \\
20.00\end{array}$ & $\begin{array}{l}05.30- \\
22.00\end{array}$ & $\begin{array}{l}05.45- \\
17.45\end{array}$ & 1 & Kurang \\
\hline 9 & $\begin{array}{l}\text { Kecepatan Perjalanan Rata- } \\
\text { Rata }\end{array}$ & $\mathrm{Km} / \mathrm{Jam}$ & $<5$ & $5-10$ & $>10$ & 37 & 3 & Baik \\
\hline \multicolumn{7}{|c|}{ TOTAL PENILAIAN } & 20 & Baik \\
\hline
\end{tabular}


Hasil analisis kinerja operasional pelayanan angkutan umum berdasarkan standar pelayanan angkutan umum dari Dirjen Perhubungan Darat menunjukkan nilai bobot masing-masing indikator, sehingga menghasilkan total nilai bobot 17. Maka kinerja pelayanan BRT pada koridor II Terminal Terboyo-Terminal Sisemut dapat dikategorikan baik.

\subsection{Kebutuhan Angkutan Umum}

Berdasarkan hasil analisis jumlah BRT, total jumlah kendaraan yang dibutuhkan untuk koridor II Terminal Terboyo-Terminal Sisemut PP adalah 21 armada. Data jumlah armada yang memiliki izin adalah sebanyak 26 unit armada. Sehingga masih terdapat kelebihan 5 unit armada untuk melayani koridor ini. Dari hasil analisa kebutuhan jumlah BRT pada koridor ini mengalami kelebihan jumlah armada. Untuk sementara, sebaiknya jumlah angkutan umum yang sudah ada dipertahankan dan tidak perlu ada penambahan jumlah armada lagi. Hal ini disebabkan karena rata- rata kendaraan yang beroperasi setiap hari pada koridor ini hampir mendekati hasil analisa kebutuhan jumlah angkutan umum.

\subsection{Hasil Evaluasi Kinerja Operasional Pelayanan \\ Dari hasil analisa, pembahasan dan} melihat kondisi operasional pelayanan Bus Rapid Ttansit (BRT) Koridor II Terminal Terboyo - Terminal Sisemut PP ditemukan beberapa permasalahan sebagai berikut: Koridor II merupakan koridor yang sibuk, karena merupakan jalan keluar masuk Kota Semarang ke Solo/Jogja dan Surabaya. Dengan adanya BRT yang melayani koridor II diharapkan dapat membantu mengatasi kemacetan di Kota Semarang. Namun dalam pengoperasian BRT koridor II ini masih ditemui beberapa kendala seperti tingkat pelayanan yang rendah menyangkut sarana dan prasarana yang kurang memadai, waktu tempuh yang cukup lama, jumlah penumpang yang melebihi kapasitas angkut, dan tingkat kenyamanan yang rendah.

\section{SIMPULAN}

\subsection{Kesimpulan}

Dalam upaya mengatasi kemacetan di ruas-ruas jalan Kota Semarang, Pemerintah Kota Semarang mengembangkan transportasi massal yang murah, aman dan nyaman yaitu Bus Rapid Transit (BRT). Pelayanan BRT harus selalu terus ditingkatkan agar dapat memenuhi kebutuhan masyarakat. Oleh karena itu perlu dilakukan analisis tentang kinerja BRT untuk mengetahui apa saja yang perlu ditingkatkan untuk meningkatkan kenyamanan kenyamanan masyarakat dalam mengakses BRT

Berdasarkan hasil analisis, kriteria kinerja pelayanan yang termasuk dalam kategori baik adalah waktu perjalanan, headway, kecepatan perjalanan dan waktu tunggu. Kriteria kinerja BRT yang termasuk dalam kategori sedang yaitu waktu pelayanan, serta kriteria kinerja BRT yang termasuk kategori kurang adalah load factor dinamis, jumlah kendaraan beroperasi, dan awal \& akhir perjalanan. Sehingga kinerja operasional pelayanan BRT koridor II Terminal TerboyoTerminal Sisemut PP jika ditarik total nilai bobotnya adalah sebanyak 20 yaitu termasuk dalam kategori baik.

\subsection{Rekomendasi}

Adapun rekomendasi yang dapat diberikan berdasarkan penelitian ini adalah sebagai berikut:

1. Pembuatan jalur khusus untuk BRT agar waktu perjalanan lebih cepat, sehingga pengguna lebih minat dalam menggunakan BRT.

2. Perbaikan sistem parkir dibadan jalan, beberapa halte tidak dapat untuk merapatkan bus karena banyak becak, motor dan mobil yang berhenti di halte sehingga menghalangi penumpang yang ingin naik dan turun.

3. Meningkatkan awal \& akhir perjalanan karena belum sesuai standar perhitungan yang telah ditetapkan oleh Departemen Perhubungan.

4. Penambahan armada pada jam sibuk untuk mengurangi penumpukan penumpang. 


\section{REFERENSI}

Hadi, A.F. (2001). Evaluasi Kinerja Angkutan Umum Rute Terminal-Kampus Universitas Timor Kota Kefamenanu. Skripsi Universitas Nusa Cendana Kupang.

Nadi, M.A.B., (2018). Analisa Pemilihan Moda Transportasi Umum Rute Tanjung Karang - Bandara Radin Inten II Dengan Stated Preference dan Uji Crame's V. Borneo Engineering: Jurnal Teknik Sipil, 2(2), 137147. Doi: $10.35334 /$ be.v2i2.621

Pradipta, E.G., Suroso, Suharini, E. (2014). Efektivitas BRT (Bus Rapid Transit) Trans Semarang Sebagai Moda Transportasi di Kota Semarang. Jurnal Geo-Image, 3(2), doi: 10.15294/geoimage.v3i2.4659

Pradita, F., dkk. (2016). Kajian Kinerja Pelayanan Bus Rapid Transit (BRT) Kabupaten Sidoarjo. Jurnal Mahasiswa Teknik Sipil, 1 (2), 696-710. http://sipil.studentjournal.ub.ac.id/index.ph p/jmts/article/view/355

Rahmawati, C Dan Yeni Novitasari. (2010). Evaluasi Kinerja Angkutan Kota Semarang Studi Kasus Bus Damri Ac B 04 Trayek Ngaliyan-Pucang Gading Dan Bus Brt Trayek Mangkang-Penggaron. Tugas Akhir Universitas Diponegoro.

Safe, Y.T., Udiana, I Made \& Bella, R.A. (2015). Evaluasi Kinerja Angkutan Umum Trayek Terminal Oebobo - Terminal Kupang PP Dan Terminal Kupang - Terminal Noelbaki PP. Jurnal Teknik Sipil, IV (1), 65-78. https://scriptura.petra.ac.id/index.php/jurn al-teknik-sipil/issue/view/3218

Susilowati, Wicaksono, A \& Suharso, T.W. (2011). Kajian Kinerja Angkutan Umum Dengan Metode Quality Function Deployment (QFD) Pada Kawasan Industri Marmer di Kabupaten Tulungagung. Jurnal Rekayasa Sipil, 5 (3), 191-200.

https://rekayasasipil.ub.ac.id/index.php/rs/ article/view/205
Tamin, Oz., (2008). Perencanaan, Pemodelan, \& Rekayasa Transportasi: Teori, Contoh Soal, Dan Aplikasi. Bandung: Penerbit ITB. 